University of Wollongong

Research Online

Australian Institute for Innovative Materials -

Papers

Australian Institute for Innovative Materials

$1-1-2017$

\title{
Superior Li storage anode based on novel Fe-Sn-P alloy prepared by electroplating
}

Xiao Zheng

China Jiliang University

Peng Zhang

China Jiliang University

Liang Wang

China Jiliang University

Shan Tao

China Jiliang University

Yunxiao Wang

University of Wollongong, yunxiao@uow.edu.au

See next page for additional authors

Follow this and additional works at: https://ro.uow.edu.au/aiimpapers

Part of the Engineering Commons, and the Physical Sciences and Mathematics Commons

Research Online is the open access institutional repository for the University of Wollongong. For further information contact the UOW Library: research-pubs@uow.edu.au 


\title{
Superior Li storage anode based on novel Fe-Sn-P alloy prepared by electroplating
}

\author{
Abstract \\ Novel ternary Fe-Sn-P alloys prepared by simple single-step electrodeposition are investigated as \\ promising anodes for Li-ion batteries. The Fe $51 \mathrm{Sn} 38 \mathrm{P} 11$ electrode, in particular, shows outstanding Li- \\ storage properties, with initial specific discharge/charge capacities of 857.8 and $655 \mathrm{~mA} \mathrm{~h} \mathrm{~g} i 1$, \\ respectively. The reversible capacity remains stable at $427 \mathrm{~mA} \mathrm{~h} \mathrm{~g} i 1$, even after 90 cycles, \\ corresponding to a coulombic efficiency of $96 \%$ and a capacity retention of $65 \%$. The cauliflower-like \\ morphology of the above anode is well preserved after 90 cycles, suggesting that this alloy could \\ significantly mitigate the electrode volume expansion by exerting a positive multiphase synergistic effect. \\ The superior electrochemical performance of the ternary Fe-Sn-P alloys confirmed its potential as an \\ alternative Li-ion storage anode; the large-scale suitability of the developed electroplating method \\ provides an additional advantage. \\ Disciplines \\ Engineering | Physical Sciences and Mathematics

\section{Publication Details} \\ Zheng, X., Zhang, P., Wang, L., Tao, S., Wang, Y., Huang, L., Sun, S. \& Li, J. (2017). Superior Li storage anode \\ based on novel Fe-Sn-P alloy prepared by electroplating. Electrochimica Acta, 247 314-320.

\section{Authors} \\ Xiao Zheng, Peng Zhang, Liang Wang, Shan Tao, Yunxiao Wang, Ling Huang, Jun-Tao Li, and Shi-Gang Sun
}




\title{
Superior Li storage anode based on novel Fe-Sn-P alloy prepared by electroplating
}

\author{
Xiao-Mei Zheng ${ }^{\mathrm{a}^{*}}$, Peng-Yue Zhang ${ }^{\mathrm{a}^{*}}$, Liang-ke Wang ${ }^{\mathrm{a}}$, Shan Tao ${ }^{\mathrm{a}}$, Yun-Xiao Wang ${ }^{\mathrm{c}}$, Ling Huang ${ }^{\mathrm{b}}$, \\ Jun-Tao Li ${ }^{\mathrm{b}}$, Shi-Gang Sun ${ }^{\mathrm{b}}$ \\ a. China Jiliang University, Magnetism Key Lab Zhejiang Province, Hangzhou, 310018, China. \\ b. Department of chemistry, College of Chemistry and Chemical Engineering, State key laboratory of physical \\ chemistry of solid surfaces, Xiamen University, Xiamen, 361005, China \\ c. Institute for Superconducting \& Electronic Materials (ISEM) Innovation Campus, University of Wollongong, \\ Wollongong, NSW, 2519 (Australia)
}

${ }^{*}$ Corresponding author. Tel.: +86-571-87676238; fax: +86-571-87676238

E-mail: Zheng_xiaomei@cjlu.edu.cn or Zhang_pengyue@cjlu.edu.cn

\begin{abstract}
Novel ternary Fe-Sn-P alloys prepared by simple single-step electrodeposition are investigated as promising anodes for Li-ion batteries. The $\mathrm{Fe}_{51} \mathrm{Sn}_{38} \mathrm{P}_{11}$ electrode, in particular, shows outstanding Li-storage properties, with initial specific discharge/charge capacities of 857.8 and $655 \mathrm{~mA} \mathrm{~h} \mathrm{~g}^{-1}$, respectively. The reversible capacity remains stable at $427 \mathrm{~mA} \mathrm{~h} \mathrm{~g}^{-1}$, even after 90 cycles, corresponding to a coulombic efficiency of $96 \%$ and a capacity retention of $65 \%$. The cauliflower-like morphology of the above anode is well preserved after 90 cycles, suggesting that this alloy could significantly mitigate the electrode volume expansion by exerting a positive multiphase synergistic effect. The superior electrochemical performance of the ternary Fe-Sn-P alloys confirmed its potential as an alternative Li-ion storage anode; the large-scale suitability of the developed electroplating method provides an additional advantage.
\end{abstract}

Keywords: metal phosphides; tin-based anode; lithium-ion battery; electrodeposition; negative electrode 


\section{Introduction}

Rechargeable Li-ion batteries (LIBs), as well as supercapacitors, exhibit high power density, high safety, and long lifetimes, thereby playing an important role in our daily life because they are widely used in electronic devices, implantable medical devices, smart grid systems, and vehicles [1-5]. However, the accessible capacities of Li-ion batteries still cannot meet the fast-growing energy demand of newly emerging applications such as electric vehicles. Therefore, the development of anode materials with high capacities and superior cyclabilities as alternatives to graphite materials (372 $\mathrm{mA} \mathrm{h} \mathrm{g}^{-1}$ ) for Li-ion batteries has become increasingly important. Among the various potential anode materials, phosphorus has recently attracted much attention because of its high theoretical discharge capacity (2596 $\mathrm{mA} \mathrm{h}^{-1}$ ), unique puckered layer structure, and low Li intercalation potential (0.02-0.2 V) [6-8]. The puckered layer structure with a low stacking density of $30 \%$ can release structural strain and enable fast diffusion of $\mathrm{Li}^{+}$, thus enhancing the electrochemical cycling stability. Because the electronic conductivity of $\mathrm{P}$ is rather poor, extensive research has been conducted on transition metal phosphides (MPs) that can effectively improve the overall electronic conductivity of the electrode, affording enhanced Li-storage properties [9-11]. However, the commercial application of MP anodes is hindered by their large volume changes upon Li insertion and extraction that result in particle pulverization and rapid capacity fading [12]. So far, various binary $\mathrm{MPs}$ such as $\mathrm{MnP}_{4}, \mathrm{FeP}_{x}, \mathrm{CoP}_{3}, \mathrm{Cu}_{3} \mathrm{P}, \mathrm{NiP}_{2}$, $\mathrm{SnP}_{0.94}$, and $\mathrm{Sn}_{4} \mathrm{P}_{3}$ have been fabricated via high-temperature solid-state synthesis, ball milling, solution-phase techniques, and other traditional time-consuming and high-cost stepwise methods $[7,9,12-18]$, which often require extreme operating conditions incompatible with practical applications.

In recent years, ternary metal phosphides (e.g., Sb-Co-P, Fe-Sb-P, and Sn-Ni-P) and even a 
quaternary Fe-Sn-Sb-P system have been explored as alternatives to binary MPs [19-22]. The introduction of inactive elements $(\mathrm{Fe} / \mathrm{Ni} / \mathrm{Co})$ can not only effectively alleviate the mechanical stress induced by active phase $(\mathrm{Sn} / \mathrm{Sb} / \mathrm{P})$ volume changes, but also enhance electron transfer and dynamic/mechanical strength. More importantly, these ternary/quaternary phosphides can be prepared via single-step electroplating, which is cost-effective and easy to scale-up, allowing facile film deposition onto substrates. In addition, the electroplating technique is flexible and adjustable, allowing one to control the composition, morphology, and thickness of the produced thin films via a simple variation of the current density and plating time.

Herein, we report a novel multiphase Fe-Sn-P composite via a facile single-step electroplating method. Five ternary Fe-Sn-P alloys of different compositions were electrochemically deposited on copper foil substrates; the optimal performance was observed for $\mathrm{Fe}_{51} \mathrm{Sn}_{38} \mathrm{P}_{11}$. The Fe-Sn-P alloys were used to prepare a binder-free LIB anode, delivering high capacity and superior cycling performance. Thus, these alloys hold great promise as a superior Li storage anode.

\section{Experimental section}

\subsection{Linear sweep voltammetry (LSV) characterization}

All electrochemical analyses were conducted using an electrochemical workstation (CHI660C, Chenhua Instruments, China) and a three-electrode setup. A Pt sheet (exposed area $=2 \mathrm{~cm}^{2}$ ) and a glassy carbon electrode (diameter $=0.5 \mathrm{~mm}$ ) were employed as the counter and working electrodes, respectively, and the potential applied between them was regulated using a reference saturated calomel electrode (SCE).

\subsection{Fabrication of Fe-Sn-P.multiphase composite electrodes}

Fe-Sn-P alloys were galvanostatically fabricated at room temperature using a potentiostat; the composition, content, and function of each reagent are listed in Table 1. The $\mathrm{pH}$ was adjusted to 
1.5 by utilizing $1 \mathrm{M}$ hydrochloric acid. All chemicals were of reagent grade and were dissolved in distilled water. A Pt foil with an area of $4 \mathrm{~cm}^{2}$ was used as a counter electrode, with the SCE used as a reference. Fe-Sn-P electrodes were deposited on $\mathrm{Cu}$ foil circles (diameter $=1.6 \mathrm{~cm}$, exposed surface area $=2.0 \mathrm{~cm}^{2}$ ) at an applied current density of $8.85-44.25 \mathrm{~A} \mathrm{dm}^{-2}$ for $2 \mathrm{~min}$.

\subsection{Material characterization}

The crystal structures of the deposited materials were investigated by powder X-ray diffraction (XRD; Philips X'pert Pro Super X-ray diffractometer, Netherlands, $\mathrm{Cu} K_{\alpha}$ radiation, $\lambda=1.5408 \AA$ ) at a scan rate of $2^{\circ} \min ^{-1}$. The morphology and elemental composition of the electrodeposited films were determined by field emission scanning electron microscopy (SEM, Hitachi S-4800) coupled with energy dispersive X-ray spectroscopy (EDX). The binding energies of Fe, Sn, and P in as-prepared Fe-Sn-P alloys were determined by X-ray photoelectron spectroscopy (XPS, Quantum 2000 spectrometer, USA)

\subsection{Electrochemical performance characterization}

As-deposited Fe-Sn-P electrodes were heated to $80{ }^{\circ} \mathrm{C}$ under vacuum for $12 \mathrm{~h}$, and their electrochemical behavior was characterized using a two-electrode cell; a lithium foil was used as a reference/counter electrode. All CR2025 coin cells were assembled in an Ar-filled glove box (with $\mathrm{H}_{2} \mathrm{O}$ and $\mathrm{O}_{2}$ levels being less than $2 \mathrm{ppm}$ ). The electrolyte corresponded to a $1.0 \mathrm{M}$ solution of $\mathrm{LiPF}_{6}$ in a mixture of diethyl carbonate (DEC), dimethyl carbonate (DMC), and ethylene carbonate (EC) (DEC:DMC:EC = 1:1:1 v/v/v) containing $2 \mathrm{wt} \%$ of vinylene carbonate (VC, provided by Guangzhou Tinci Materials Technology Co., Ltd., China). A Celgard 2400 polypropylene membrane was used as a separator.

Galvanostatic charge-discharge tests of $\mathrm{Li} / \mathrm{Fe}-\mathrm{Sn}-\mathrm{P}$ half-cells were performed using a LAND-V34 (Wuhan, China) battery tester at a rate of $100 \mathrm{~mA} \mathrm{~g}^{-1}$ in a fixed voltage range of 
1.5-0.02 V at room temperature. The cycled electrodes were dismantled in the glove box, washed with DMC and acetone for three times, and reserved in a special box sealed with epoxy resin glue prior to SEM measurements.

\section{Results and discussion}

Fe-P and Fe-Sn-P films deposited on the $\mathrm{Cu}$ substrate were characterized by cathodic LSV, which was performed in cathodic direction from -0.6 to $-1.15 \mathrm{~V}$ at room temperature and a scan rate of $5 \mathrm{mV} \mathrm{s}^{-1}$ (Fig. 1a). Curve 1 (red line in Fig. 1a) was recorded in a solution of $0.6 \mathrm{M}$ $\mathrm{H}_{3} \mathrm{BO}_{3}, 1.0 \mathrm{M} \mathrm{NH} 4 \mathrm{Cl}, 0.5 \mathrm{M} \mathrm{NaH}_{2} \mathrm{PO}_{2} \cdot \mathrm{H}_{2} \mathrm{O}$, and $0.05 \mathrm{M} \mathrm{FeCl}_{2} \cdot 4 \mathrm{H}_{2} \mathrm{O}$. A rapid increase in current density was observed between -1.09 and $-1.5 \mathrm{~V}$ (vs. SCE), associated with Fe-P electrodeposition and simultaneous evolution of hydrogen, in agreement with a previous study [20]. Significant changes were observed upon incorporation of $\mathrm{Sn}^{2+}$ ions into the $\mathrm{Fe}-\mathrm{P}$ system, such as the appearance of a new reduction peak at around $-0.65 \mathrm{~V}$ (curve 2, black line). This peak was attributed to the deposition of $\mathrm{Sn}$, as confirmed by SEM and EDX (inset) measurements (Fig. 1b). Ternary alloy deposition occurred at potentials more negative than -1.0 V. Under these conditions, curve 2 was observed to have a higher current density than curve 1 because of the electrodeposition of $\mathrm{Sn}$ on the $\mathrm{Cu}$ substrate. To confirm $\mathrm{Sn}$ deposition at $-0.65 \mathrm{~V}$, a thin film was deposited on the $\mathrm{Cu}$ substrate from the same solution at $-0.65 \mathrm{~V}$ for $10 \mathrm{~min}$. The corresponding SEM image in Fig. 1b shows numerous stripes on the thin film surface, without any other special features. As illustrated in the inset of Fig. 1b, EDX results demonstrate that the deposit obtained at $-0.65 \mathrm{~V}$ consists of $\mathrm{Sn}$, and the weak intensity of the Sn peak indicates the low amount of this metal. The peak of $\mathrm{Cu}$ was attributed to the $\mathrm{Cu}$ matrix. No peaks of other elements were observed, implying that pure $\mathrm{Sn}$ was deposited at around $-0.65 \mathrm{~V}$. When cathodic scanning was carried out at $-1.5 \mathrm{~V}$, a ternary Fe-Sn-P alloy was obtained. As shown in Fig. 1c, 
the SEM image reveals that the as-deposited Fe-Sn-P (denoted as $\mathrm{Fe}_{51} \mathrm{Sn}_{38} \mathrm{P}_{11}$ ) exhibits uniform and compact packing without holes or cracks. It features cauliflower-like aggregates composed of nanoparticles, most of which are spherical and exhibit sizes between 50 and $1.5 \mu \mathrm{m}$. This cauliflower-like morphology provides more active sites for electrochemical reactions due to its large specific surface area, as compared to those of planar or spherical particles. This morphology effectively alleviates the volume expansion induced by repeated $\mathrm{Li}^{+}$insertion and extraction. Moreover, the elemental mappings of element $\mathrm{Fe}, \mathrm{Sn}$, and P shown in Figs. 1d-f confirm that these elements are homogenously dispersed in the composite without any impurity.

The reactions on the $\mathrm{Cu}$ surface can be expressed as follows [23]:

$$
\begin{aligned}
\mathrm{H}_{2} \mathrm{PO}_{2}^{-}+2 \mathrm{H}^{+}+e^{-} & \rightarrow \mathrm{P}+2 \mathrm{H}_{2} \mathrm{O} \\
\mathrm{Fe}^{2+}+2 e^{-} & \rightarrow \mathrm{Fe} \\
\mathrm{Sn}^{2+}+2 e^{-} & \rightarrow \mathrm{Sn} \\
2 \mathrm{H}^{+}+2 e^{-} & \rightarrow \mathrm{H}_{2} \uparrow
\end{aligned}
$$

Generally, the deposit composition is significantly affected by current densities. Therefore, five Fe-Sn-P alloys of different compositions ( $\mathrm{Fe}_{51} \mathrm{Sn}_{38} \mathrm{P}_{11}, \mathrm{Fe}_{58} \mathrm{Sn}_{30} \mathrm{P}_{12}, \mathrm{Fe}_{70} \mathrm{Sn}_{16} \mathrm{P}_{14}, \mathrm{Fe}_{75} \mathrm{Sn}_{10} \mathrm{P}_{15}$, and $\left.\mathrm{Fe}_{73} \mathrm{Sn}_{13} \mathrm{P}_{14}\right)$ were electrochemically deposited from the same electrolyte at various current densities (Table 2 and Fig. 2a). The contents of $\mathrm{Fe}$ and $\mathrm{P}$ in these alloys increased with increasing current density, whereas that of Sn concomitantly decreased. The crystalline phases of the as-deposited Fe-Sn-P alloys were further probed by XRD (Fig. 2b). The peaks of $\mathrm{Fe}_{3} \mathrm{Sn}(2 \theta=$

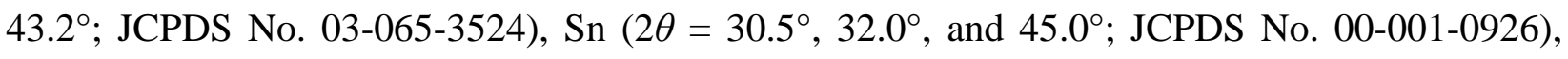
and $\operatorname{SnP}\left(2 \theta=86.0^{\circ}\right.$; JCPDS No. 00-021-1230) were clearly identified for $\mathrm{Fe}_{51} \mathrm{Sn}_{38} \mathrm{P}_{11}$ deposited at $8.85 \mathrm{~A} \mathrm{dm}^{-2}$; no other peaks were detected except for those of the $\mathrm{Cu}$ substrate $\left(2 \theta=50.4^{\circ}\right.$, $74.0^{\circ}$, and $89.9^{\circ}$ ). For $\mathrm{Fe}_{58} \mathrm{Sn}_{30} \mathrm{P}_{12}$, the peak of $\mathrm{SnP}$ was not observed, and the intensities of the 
$\mathrm{Fe}_{3} \mathrm{Sn}$ and Sn peaks were weaker than those of $\mathrm{Fe}_{51} \mathrm{Sn}_{38} \mathrm{P}_{11}$. When the current density was increased to $26.5-44.25 \mathrm{~A} \mathrm{dm}^{-2}$, a broad peak was observed at $40-45^{\circ}$, indicating that the Fe-Sn-P alloys deposited under these conditions were amorphous due to their high P content (as determined by EDX) $[24,25]$. Besides, a very weak peak of $\mathrm{Fe}_{3} \mathrm{Sn}$ was observed at $2 \theta=43.2^{\circ}$ (JCPDS No. 03-065-3524), indicating that the content of this phase in the above alloys was very low. Thus, increasing current density induced a crystalline-to-amorphous structural transition, allowing the preparation of two multiphase and three amorphous Fe-Sn-P electrodes at low and high current densities, respectively. When a Fe-Sn-P multi-phase composite electrode was used an LIB anode, the inactive Fe component therein maintained good electronic conduction and could withstand the mechanical stress induced by the alloying/de-alloying of $\mathrm{P}$ and $\mathrm{Sn}$ with $\mathrm{Li}^{+}$ because the electrode exhibits excellent mechanical strength, chemical inertness, and electrical conductivity. Furthermore, Fe played an important barrier role, preventing the agglomeration of active materials ( $\mathrm{Sn}$ and $\mathrm{P}$ ) and enhancing the cycling performance during the charge/discharge processes [26-29]. Thus, such multiphase Fe-Sn-P alloy electrodes were expected to exhibit better cycling performance than their amorphous counterparts.

The chemical composition of the Fe-Sn-P alloy deposited at $8.85 \mathrm{~A} \mathrm{dm}^{-2}$ was examined by EDX. Figure 3a presents the EDX spectrum of $\mathrm{Fe}_{51} \mathrm{Sn}_{38} \mathrm{P}_{11}$, revealing the presence of Fe, Sn, and $\mathrm{P}$ only, with the exception of substrate-originated $\mathrm{Cu}$. The weaker intensities of $\mathrm{Sn}$ and $\mathrm{P}$ peaks compared to that of the Fe peak indicate the lower contents of these elements in the alloy. The presence of $\mathrm{Fe}_{51} \mathrm{Sn}_{38} \mathrm{P}_{11}$ was further confirmed by XPS, with the corresponding spectrum (Fig. $\mathbf{3 b}$ ) showing major peaks at $\sim 130$ (P 2p), 500 (Sn 3d), and 724 (Fe 2p) eV, confirming the simultaneous presence of $\mathrm{Fe}, \mathrm{P}$, and $\mathrm{Sn}$, in agreement with the results of EDX analysis.

To further investigate the effects of composition and structure on the electrochemical 
performance, three sample Fe-Sn-P alloys prepared at $8.85,26.5$, and $44.25 \mathrm{~A} \mathrm{dm}^{-2}$ were investigated as anodes in half-cell LIBs. Their Li storage behavior is shown in Fig. 4. Using the multielectron reactions $\left(\mathrm{Sn}+4.4 \mathrm{Li} \leftrightharpoons \mathrm{Li}_{4} 4 \mathrm{Sn} ; \mathrm{P}+3 \mathrm{Li} \leftrightharpoons \mathrm{Li}_{3} \mathrm{P}\right)$ [30], the theoretical capacities of $\mathrm{Fe}_{51} \mathrm{Sn}_{38} \mathrm{P}_{11}, \mathrm{Fe}_{70} \mathrm{Sn}_{16} \mathrm{P}_{14}$, and $\mathrm{Fe}_{73} \mathrm{Sn}_{13} \mathrm{P}_{14}$ were calculated to be 698.3 , 481.3, and $439.4 \mathrm{~mA} \mathrm{~h}$ $\mathrm{g}^{-1}$, respectively. The battery with the $\mathrm{Fe}_{51} \mathrm{Sn}_{38} \mathrm{P}_{11}$ anode is expected to deliver the best electrochemical performance. As shown in Fig. 4a, b, and c, $\mathrm{Fe}_{51} \mathrm{Sn}_{38} \mathrm{P}_{11}, \mathrm{Fe}_{70} \mathrm{Sn}_{16} \mathrm{P}_{14}$, and $\mathrm{Fe}_{73} \mathrm{Sn}_{13} \mathrm{P}_{14}$ displayed the initial discharge capacities of 857.8 , 609, and $612.6 \mathrm{~mA} \mathrm{~h} \mathrm{~g}{ }^{-1}$, respectively, at a current density of $100 \mathrm{~mA} \mathrm{~g}^{-1}$. Using the corresponding charge capacities of 655 , 476, and $474 \mathrm{~mA} \mathrm{~h} \mathrm{~g}^{-1}$, the initial coulombic efficiencies were estimated as $76 \%, 78 \%$, and $77 \%$, respectively. According to previous studies [31, 32], low initial coulombic efficiencies are caused by the electrolyte decomposition (DMC and DEC), irreversible reaction of oxide impurities, and formation of a solid electrolyte interface (SEI) layer on the electrode surface. Importantly, the greatly increased coulombic efficiency (>96\%) observed from the second cycle onwards demonstrates that such irreversible reactions were significantly suppressed by SEI layer formation on the electrode surfaces of these three samples. After 90 cycles, the capacities of the $\mathrm{Fe}_{70} \mathrm{Sn}_{16} \mathrm{P}_{14}$ and $\mathrm{Fe}_{73} \mathrm{Sn}_{13} \mathrm{P}_{14}$ anodes significantly decreased. Conversely, $\mathrm{Fe}_{51} \mathrm{Sn}_{38} \mathrm{P}_{11}$ exhibited the highest discharge and charge capacities (857.8 and $427 \mathrm{~mA} \mathrm{~h} \mathrm{~g}^{-1}$, respectively) and retained the best cycling performance, which was attributed to its optimized composition. In Fe-Sn-P alloys, lithium intercalation is enabled by the presence of both $\mathrm{Sn}$ and $\mathrm{P}$, which react with $\mathrm{Li}^{+}$at $0.05-0.4$ and $0.02-0.2 \mathrm{~V}$ (vs. $\mathrm{Li}^{+} / \mathrm{Li}$ ), respectively. When $\mathrm{Li}^{+}$reacts with $\mathrm{Sn}$ at a higher voltage, $\mathrm{P}$ and $\mathrm{Fe}$ act as an inactive matrix to alleviate the volume change of Sn. Similarly, the insertion of Li ions into $\mathrm{P}$ to form $\mathrm{Li}_{x} \mathrm{P}$ at a lower voltage is buffered by the $\mathrm{Li}$-Sn alloy. Moreover, the introduced inactive Fe-containing intermetallic compound $\left(\mathrm{Fe}_{3} \mathrm{Sn}\right)$ increases the electronic conductivity and 
acts as a buffer matrix, thereby improving the cell cyclability. The above XRD analysis results show that even though $\mathrm{Fe}_{51} \mathrm{Sn}_{38} \mathrm{P}_{11}$ is crystalline and $\mathrm{Fe}_{70} \mathrm{Sn}_{16} \mathrm{P}_{14}$ and $\mathrm{Fe}_{73} \mathrm{Sn}_{13} \mathrm{P}_{14}$ are amorphous, all three samples exhibit a similar cycling trend with different capacities, indicating that the cycling performance of Fe-Sn-P alloy electrodes depends on the phase composition but not on the crystal structure. The high discharge/charge capacity of $\mathrm{Fe}_{51} \mathrm{Sn}_{38} \mathrm{P}_{11}$ was ascribed to its higher $\mathrm{Sn}$ content than that of $\mathrm{Fe}_{70} \mathrm{Sn}_{16} \mathrm{P}_{14}$ and $\mathrm{Fe}_{73} \mathrm{Sn}_{13} \mathrm{P}_{14}$, as determined by EDX analysis. Since pure $\mathrm{Sn}$ was not detected by XRD, the Sn contained in this alloy could react with lithium to deliver lithium storage capacity. Thus, $\mathrm{Fe}_{51} \mathrm{Sn}_{38} \mathrm{P}_{11}$, with the highest $\mathrm{Sn}$ content, showed better electrochemical performance than the other two Fe-Sn-P alloy electrodes. Notably, the electrochemical performance of the developed FeSnP anode was superior to those of the Sb-Co-P and $\mathrm{Fe}-\mathrm{Sb}-\mathrm{P}$ composite electrodes reported by our group previously [19, 22].

Figure 4d depicts the discharge-charge voltage profiles of the $\mathrm{Fe}_{51} \mathrm{Sn}_{38} \mathrm{P}_{11}$ composite electrode for the $1^{\text {st }}, 2^{\text {nd }}, 30^{\text {th }}, 60^{\text {th }}$, and $90^{\text {th }}$ cycles. The sloping region at $1.5-0.8 \mathrm{~V}\left(\mathrm{vs} . ~ \mathrm{Li}^{+} / \mathrm{Li}\right)$ in the initial discharge curve was assigned to the suppression of the irreversible reaction with the electrolyte and the presence of possible oxide impurities on the anode surface. These irreversible reactions accounted for the large irreversible capacity that is often unavoidable in electrochemical cycling. Three obvious discharge curve plateaus at $0.7,0.54$, and $0.45 \mathrm{~V}$ were attributed to $\mathrm{Sn}$ alloying with $\mathrm{Li}^{+}$to form $\mathrm{Li}_{x} \mathrm{Sn}(x<2.33)$ [33]. Reactions occurring below $0.2 \mathrm{~V}$ were ascribed to the formation of $\mathrm{Li}_{3} \mathrm{P}$ [34]. The sloping region observed during charging at $0.3-1.1 \mathrm{~V}$ was assigned to $\mathrm{Li}_{x} \mathrm{Sn}$ and $\mathrm{Li}_{x} \mathrm{P}$ delithiation.

Figure 5a shows the SEM image of the $\mathrm{Fe}_{51} \mathrm{Sn}_{38} \mathrm{P}_{11}$ electrode after complete delithiation after 90 cycles, revealing that the structural integrity of the particles is well preserved despite their slightly increased size, with no evident sign of pulverization. No obvious SEI formation could be 
detected on the anode surface, indicating that the produced SEI film was transparent and very thin, achieving suitable coulombic efficiency, in agreement with the results shown in Fig. 4. Similar to the as-prepared sample (Fig. 1c), the EDX mappings after 90 cycles shown in Figs. 5b-d did not show any elemental agglomeration, in which Fe, Sn, and P are well-dispersed over the sample. It also indicates that the prepared structures can be maintained over repeated cycling process, which is consistent with the good cycling stability of $\mathrm{Fe}_{51} \mathrm{Sn}_{38} \mathrm{P}_{11}$ (Fig. 4a).

Thus, the electrochemical reaction between $\mathrm{Fe}_{51} \mathrm{Sn}_{38} \mathrm{P}_{11}$ and $\mathrm{Li}^{+}$occurred in a reversible and stable manner, with the capacity degradation caused by electric contact loss effectively suppressed. The excellent capacity storage and cycling performance was ascribed to the unique cauliflower-like morphology and multiphase composition of the $\mathrm{Fe}_{51} \mathrm{Sn}_{38} \mathrm{P}_{11}$ composite electrode, which provides elastic accommodation to restrain volume changes and electrode pulverization during discharge/charge processes.

\section{Conclusions}

In summary, we have prepared novel ternary Fe-Sn-P alloy electrodes of different compositions via single-step electroplating and examined their electrochemical performances as LIB anodes. The results revealed that the multiphase $\mathrm{Fe}_{51} \mathrm{Sn}_{38} \mathrm{P}_{11}$ electrode can exhibit outstanding cycling stability and high specific capacity, showing initial discharge and charge capacities of 857.8 and $655 \mathrm{~mA} \mathrm{~h} \mathrm{~g}^{-1}$, respectively. The corresponding charge capacity is sustained at $427 \mathrm{~mA} \mathrm{~h} \mathrm{~g}^{-1}$ over 90 cycles at a high coulombic efficiency of $96 \%$, with the charge capacity retention equaling $65 \%$. The high Li-storage capacity and superior cyclability of this ternary electrode were attributed to its cauliflower-like structure and multi-phase composition ( $\mathrm{Sn}$, $\mathrm{Fe}_{3} \mathrm{Sn}$, and $\mathrm{SnP}$ phases). Thus, this study demonstrates that it is feasible to prepare novel binderand conductive agent-free P-based electrodes for potential application in LIBs by electroplating. 


\section{Acknowledgements}

This work was supported by the National Natural Science Foundation of China (Nos. 51401199, 51401180, 51301158, and 51371163), the National Key Research and Development Program of China (No. 2016YFB0100202) and Provincial Natural Science Foundation (LR15E010001 and LQ15E010005).

\section{References}

[1] M. Armand, J.M. Tarascon, Building better batteries, Nature 451(7179) (2008) 652-657.

[2] B. Kang, G. Ceder, Battery materials for ultrafast charging and discharging, Nature 458(7235) (2009) 190-193.

[3] K.S. Kang, Y.S. Meng, J. Breger, C.P. Grey, G. Ceder, Electrodes with high power and high capacity for rechargeable lithium batteries, Science 311(5763) (2006) 977-980.

[4] Y. Yan, P. Gu, S. Zheng, M. Zheng, H. Pang, H. Xue, Facile synthesis of an accordion-like Ni-MOF superstructure for high-performance flexible supercapacitors, Journal of Materials Chemistry A 4(48) (2016) 19078-19085.

[5] Y. Yan, B. Li, W. Guo, H. Pang, H. Xue, Vanadium based materials as electrode materials for high performance supercapacitors, Journal of Power Sources 329 (2016) 148-169.

[6] C.-M. Park, H.-J. Sohn, Novel antimony/aluminum/carbon nanocomposite for high-performance rechargeable lithium batteries, Chemistry of Materials 20(9) (2008) 3169-3173.

[7] D.C.S. Souza, V. Pralong, A.J. Jacobson, L.F. Nazar, A reversible solid-state crystalline transformation in a metal phosphide induced by redox chemistry, Science 296(5575) (2002) 
2012-2015.

[8] C.-M. Park, H.-J. Sohn, Black phosphorus and its composite for lithium rechargeable batteries, Advanced Materials 19(18) (2007) 2465-2468.

[9] Y. Lu, T. Wang, X. Li, G. Zhang, H. Xue, H. Pang, Synthetic methods and electrochemical applications for transition metal phosphide nanomaterials, RSC Advances 6(90) (2016) $87188-87212$.

[10] Y. Shi, B. Zhang, Recent advances in transition metal phosphide nanomaterials: synthesis and applications in hydrogen evolution reaction, Chemical Society reviews 45(6) (2016) $1529-1541$.

[11] J.M. Cameron, R.W. Hughes, Y. Zhao, D.H. Gregory, Ternary and higher pnictides; prospects for new materials and applications, Chemical Society reviews 40(7) (2011) 4099-4118.

[12] Y. Kim, H. Hwang, C.S. Yoon, M.G. Kim, J. Cho, Reversible lithium intercalation in teardrop-shaped ultrafine $\mathrm{SnP}_{0.94}$ particles: an anode material for lithium-ion batteries, Advanced Materials 19(1) (2007) 92-96.

[13] V. Pralong, D.C.S. Souza, K.T. Leung, L.F. Nazar, Reversible lithium uptake by $\mathrm{CoP}_{3}$ at low potential: role of the anion, Electrochemistry Communications 4(6) (2002) 516-520.

[14] S. Boyanov, D. Zitoun, M. Menetrier, J.C. Jumas, M. Womes, L. Monconduit, Comparison of the electrochemical lithiation/delithiation mechanisms of $\mathrm{FeP}_{\mathrm{x}}(\mathrm{x}=1,2,4)$ based electrodes in Li-ion batteries, Journal of Physical Chemistry C 113(51) (2009) 21441-21452.

[15] J.W. Hall, N. Membreno, J. Wu, H. Celio, R.A. Jones, K.J. Stevenson, Low-temperature synthesis of amorphous $\mathrm{FeP}_{2}$ and its use as anodes for $\mathrm{Li}$ ion batteries, Journal of the American Chemical Society 134(12) (2012) 5532-5535.

[16] M. Fan, Y. Chen, Y. Xie, T. Yang, X. Shen, N. Xu, H. Yu, C. Yan, Half-cell and full-cell 
applications of highly stable and binder-free sodium ion batteries based on $\mathrm{Cu}_{3} \mathrm{P}$ nanowire anodes, Advanced Functional Materials 26(28) (2016) 5019-5027.

[17] S. Liu, J. Feng, X. Bian, J. Liu, H. Xu, Electroless deposition of $\mathrm{Ni}_{3} \mathrm{P}-\mathrm{Ni}$ arrays on 3-D nickel foam as a high performance anode for lithium-ion batteries, RSC Advances 5(75) (2015) 60870-60875.

[18] S. Liu, H. Zhang, L. Xu, L. Ma, X. Chen, Solvothermal preparation of tin phosphide as a long-life anode for advanced lithium and sodium ion batteries, Journal of Power Sources 304 (2016) 346-353.

[19] X.-M. Zheng, Y. Xiao, L. Huang, F.-S. Ke, Y. He, J.-T. Li, G.-Z. Wei, S.-G. Sun, Fabrication and electrochemical properties of novel ternary Sb-Co-P alloy electrodes for lithium-ion batteries, Electrochemistry Communications 11(9) (2009) 1803-1806.

[20] X.-M. Zheng, L. Huang, Y. Xiao, H. Su, G.-1. Xu, F. Fu, J.-T. Li, S.-G. Sun, A dicranopteris-like Fe-Sn-Sb-P alloy as a promising anode for lithium ion batteries, Chemical Communications 48(54) (2012) 6854-6856.

[21] Y.-X. Wang, L. Huang, Y.-Q. Chang, F.-S. Ke, J.-T. Li, S.-G. Sun, Fabrication and electrochemical properties of the Sn-Ni-P alloy rods array electrode for lithium-ion batteries, Electrochemistry Communications 12(9) (2010) 1226-1229.

[22] L. Huang, X.-M. Zheng, Y.-S. Wu, L.-J. Xue, F.-S. Ke, G.-Z. Wei, S.-G. Sun, Electrodeposition and lithium storage performance of novel three-dimensional porous $\mathrm{Fe}-\mathrm{Sb}-\mathrm{P}$ amorphous alloy electrode, Electrochemistry Communications 11(3) (2009) 585-588.

[23] K. Sridharan, K. Sheppard, Electrochemical characterization of Fe-Ni-P alloy electrodeposition, Journal of Applied Electrochemistry 27(10) (1997) 1198-1206.

[24] F. Wang, K. Itoh, T. Watanabe, Relationship between the crystallographic structure of 
electrodeposited Fe-P alloy film and its thermal equilibrium phase diagram, Materials Transactions 44(1) (2003) 127-132.

[25] D.S. Xue, H.G. Shi, The fabrication and characteristic properties of amorphous $\mathrm{Fe}_{1-\mathrm{x}} \mathrm{P}_{\mathrm{x}}$ alloy nanowire arrays, Nanotechnology 15(12) (2004) 1752-1755.

[26] O. Mao, J.R. Dahn, Mechanically alloyed Sn-Fe(-C) powders as anode materials for Li-ion batteries - III. $\mathrm{Sn}_{2} \mathrm{Fe}: \mathrm{SnFe}_{3} \mathrm{C}$ active/inactive composites, Journal of the Electrochemical Society 146(2) (1999) 423-427.

[27] O. Mao, R.A. Dunlap, J.R. Dahn, Mechanically alloyed Sn-Fe(-C) powders as anode materials for Li-ion batteries - I. The $\mathrm{Sn}_{2} \mathrm{Fe}-\mathrm{C}$ system, Journal of the Electrochemical Society 146(2) (1999) 405-413.

[28] F. Xin, X. Wang, J. Bai, W. Wen, H. Tian, C. Wang, W. Han, A lithiation/delithiation mechanism of monodispersed MSn5 ( $\mathrm{M}=\mathrm{Fe}$, $\mathrm{Co}$ and $\mathrm{FeCo}$ ) nanospheres, Journal of Materials Chemistry A 3(13) (2015) 7170-7178.

[29] J.T. Yin, M. Wada, S. Tanase, T. Sakai, Nanocrystalline Ag-Fe-Sn anode materials for Li-ion batteries, Journal of the Electrochemical Society 151(4) (2004) A583-A589.

[30] X.-P. Gao, H.-X. Yang, Multi-electron reaction materials for high energy density batteries, Energy \& Environmental Science 3(2) (2010) 174-189.

[31] J.-T. Li, J. Swiatowska, A. Seyeux, L. Huang, V. Maurice, S.-G. Sun, P. Marcus, XPS and ToF-SIMS study of Sn-Co alloy thin films as anode for lithium ion battery, Journal of Power Sources 195(24) (2010) 8251-8257.

[32] J.-T. Li, S.-R. Chen, X.-Y. Fan, L. Huang, S.-G. Sun, Studies of the interfacial properties of an electroplated Sn thin film electrode/electrolyte using in situ MFTIRS and EQCM, Langmuir 23(26) (2007) 13174-13180. 
[33] X. Fan, P. Dou, A. Jiang, D. Ma, X. Xu, One-step electrochemical growth of a three-dimensional Sn-Ni@PEO nanotube array as a high performance lithium-ion battery anode, ACS Applied Materials \& Interfaces 6(24) (2014) 22282-22288.

[34] S. Boyanov, J. Bernardi, F. Gillot, L. Dupont, M. Womes, J.M. Tarascon, L. Monconduit, M.L. Doublet, FeP: Another attractive anode for the Li-ion battery enlisting a reversible two-step insertion/conversion process, Chemistry of Materials 18(15) (2006) 3531-3538. 
Table 1.Composition of the bath and electroplating conditions used for the preparation of Fe-Sn-P alloys.

Table 2.Chemical composition of Fe-Sn-P alloys deposited at different current density. 


\begin{tabular}{lcl}
\hline Bath composition & Concentration (M) & Function \\
\hline $\mathrm{SnCl}_{2} \cdot 2 \mathrm{H}_{2} \mathrm{O}$ (stannous chloride) & 0.03 & Source of Sn \\
$\mathrm{H}_{3} \mathrm{BO}_{3}$ (boric acid) & 0.60 & Buffer agent \\
$\mathrm{NH}_{4} \mathrm{Cl}($ ammonium chloride) & 1.00 & Complex agent \\
$\mathrm{NaH}_{2} \mathrm{PO}_{2} \cdot \mathrm{H}_{2} \mathrm{O}$ (sodium hypophosphite) & 0.5 & Source of P \\
$\mathrm{FeCl}_{2} \cdot 4 \mathrm{H}_{2} \mathrm{O}$ (ferrous chloride) & 0.05 & Source of Fe \\
Electro-deposition parameters & value & \\
\hline $\mathrm{Current}$ density $\left(\mathrm{A} / \mathrm{dm}^{2}\right)$ & $8.85-44.25$ & \\
$\mathrm{pH}$ & 1.5 & \\
Temperature & Room temperature & \\
Plating time & 2 min & \\
\hline
\end{tabular}

Table 1 


\begin{tabular}{cccccc}
\hline $\begin{array}{c}\text { Current } \\
\text { density } \\
\mathrm{A} / \mathrm{dm}^{2}\end{array}$ & 8.85 & 17.7 & 26.5 & 35.40 & 44.25 \\
\cline { 2 - 5 } & At\% & At\% & At\% & At\% & At\% \\
\hline Fe & 50.8 & 58.2 & 70.2 & 75.0 & 73.0 \\
$\mathrm{Sn}$ & 38.1 & 30.3 & 16.1 & 10.3 & 13.2 \\
$\mathrm{P}$ & 11.1 & 11.5 & 13.7 & 14.7 & 13.8 \\
Total \% & 100 & 100 & 100 & 100 & 100 \\
\hline
\end{tabular}

Table 2 


\section{Figures and Figure Captions}

Figure 1 (a) Linear sweep voltammetry (LSV) of Fe-P and Fe-Sn-P alloy deposition in different solutions.

(1) $0.6 \mathrm{MH}_{3} \mathrm{BO}_{3}, 1.0 \mathrm{M} \mathrm{NH}_{4} \mathrm{Cl}, 0.5 \mathrm{M} \mathrm{NaH}_{2} \mathrm{PO}_{2} \cdot \mathrm{H}_{2} \mathrm{O}$, and $0.05 \mathrm{M} \mathrm{FeCl}_{2} \cdot 4 \mathrm{H}_{2} \mathrm{O}$;

(2) $0.03 \mathrm{M} \mathrm{SnCl}_{2} \cdot 6 \mathrm{H}_{2} \mathrm{O}, 0.6 \mathrm{MH}_{3} \mathrm{BO}_{3}, 1.0 \mathrm{M} \mathrm{NH}_{4} \mathrm{Cl}, 0.5 \mathrm{M} \mathrm{NaH}_{2} \mathrm{PO}_{2} \cdot \mathrm{H}_{2} \mathrm{O}$, and $0.05 \mathrm{M}$ $\mathrm{FeCl}_{2} \cdot 4 \mathrm{H}_{2} \mathrm{O}$

(b) SEM image of a Sn film deposited at $-0.65 \mathrm{~V}$ for $10 \mathrm{~min}$. The inset figure is the EDX spectrum of the Sn film deposited at $-0.65 \mathrm{~V}$ for $10 \mathrm{~min}$.

(c) SEM image of the as-prepared $\mathrm{Fe}_{51} \mathrm{Sn}_{38} \mathrm{P}_{11}$ electrode and elemental mapping images of (d) $\mathrm{Fe}$, (e) Sn, and (f) P.

Figure 2 (a) Chemical composition of Fe-Sn-P alloy film prepared at various current densities; (b) XRD patterns of Fe-Sn-P alloys with different compositions.

Figure $3 \mathrm{EDX}$ (a) and XPS spectra (b) of $\mathrm{Fe}_{51} \mathrm{Sn}_{38} \mathrm{P}_{11}$ multiphase composite electrode.

Figure 4 Lithiation/delithiation capacities and coulombic efficiency of $\mathrm{Fe}_{51} \mathrm{Sn}_{38} \mathrm{P}_{11}, \mathrm{Fe}_{70} \mathrm{Sn}_{16} \mathrm{P}_{14}$, and $\mathrm{Fe}_{73} \mathrm{Sn}_{13} \mathrm{P}_{14}(\mathrm{a}-\mathrm{c})$ and (d) galvanostatic charge-discharge curves of $\mathrm{Fe}_{51} \mathrm{Sn}_{38} \mathrm{P}_{11}$ multiphase composite electrode in the fixed voltage range of $1.5-0.02 \mathrm{~V}$ at a current density of $100 \mathrm{~mA} \mathrm{~g}^{-1}$.

Figure 5 (a) SEM image of $\mathrm{Fe}_{51} \mathrm{Sn}_{38} \mathrm{P}_{11}$ electrode after 90 cycles and elemental mapping images of (b) Fe, (c) Sn, and (d) P. 

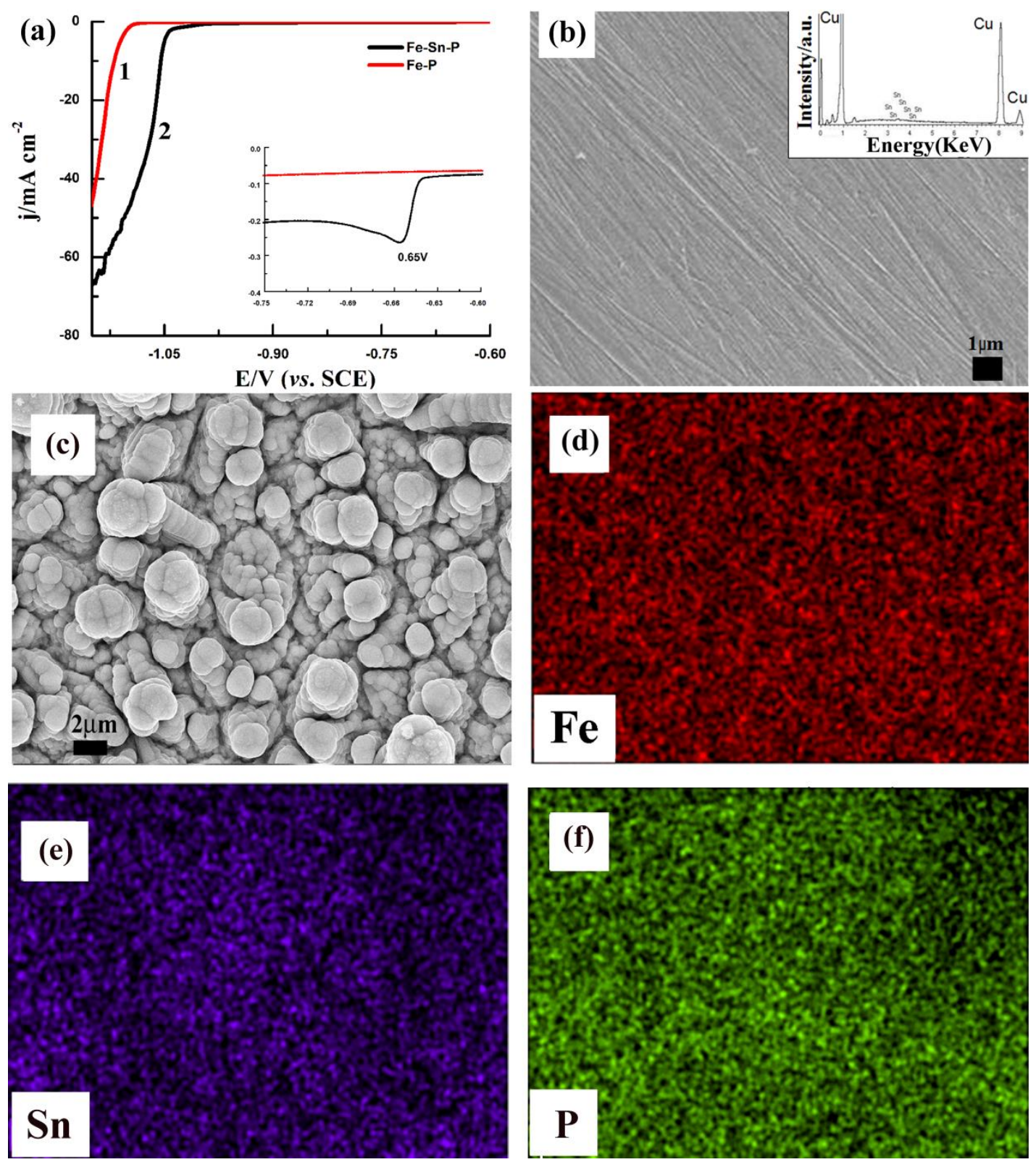

Figure 1 

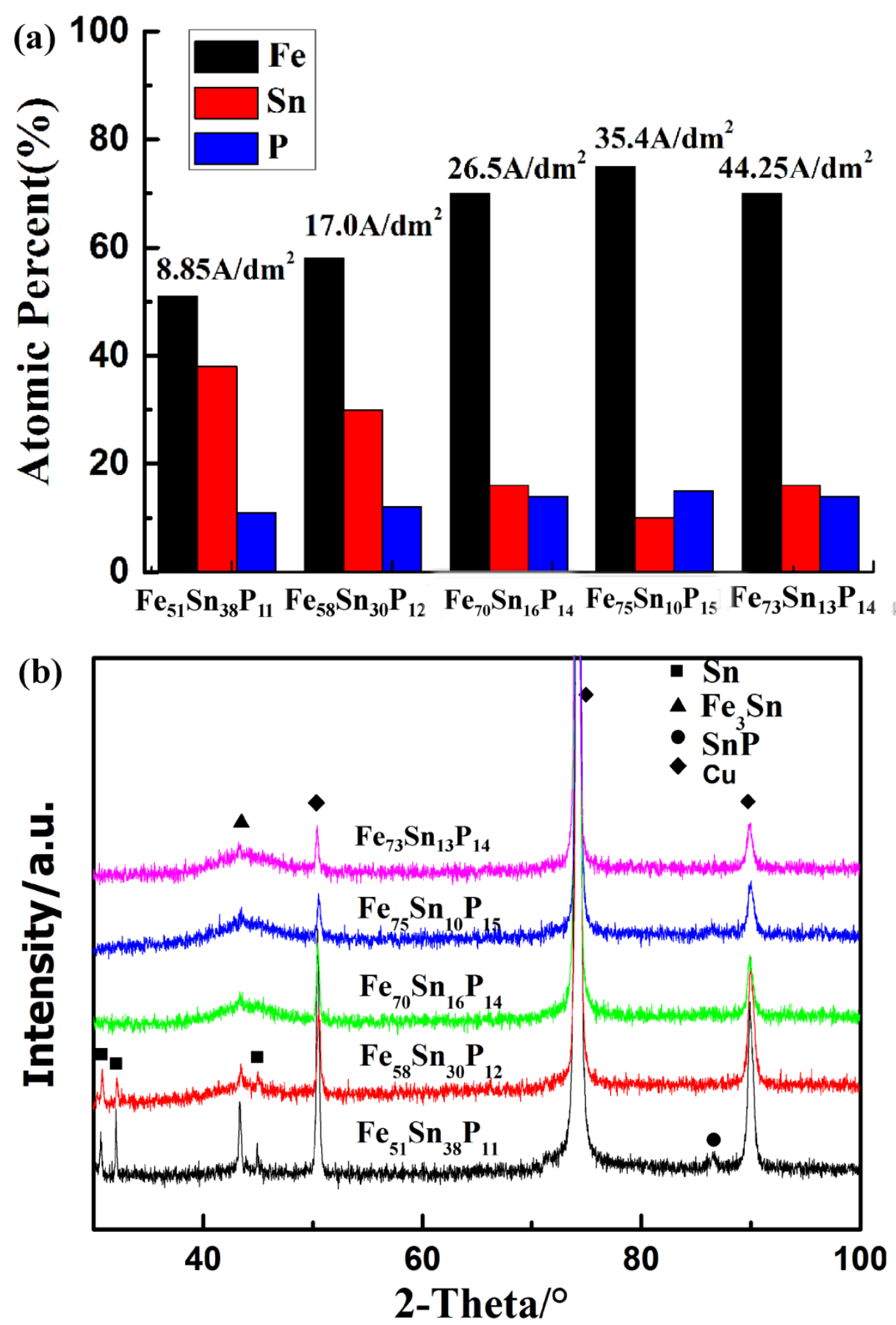

Figure 2 

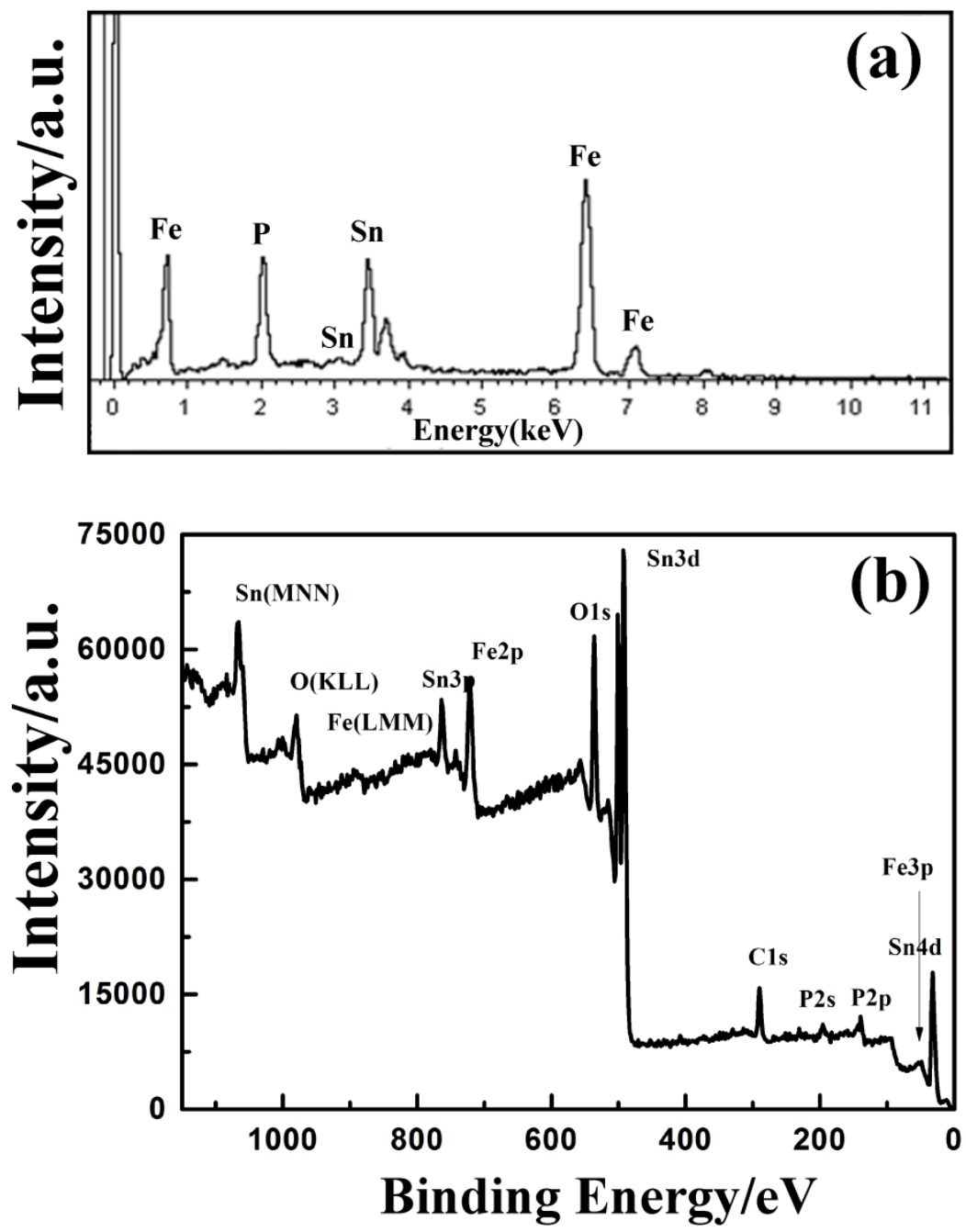

Figure 3 

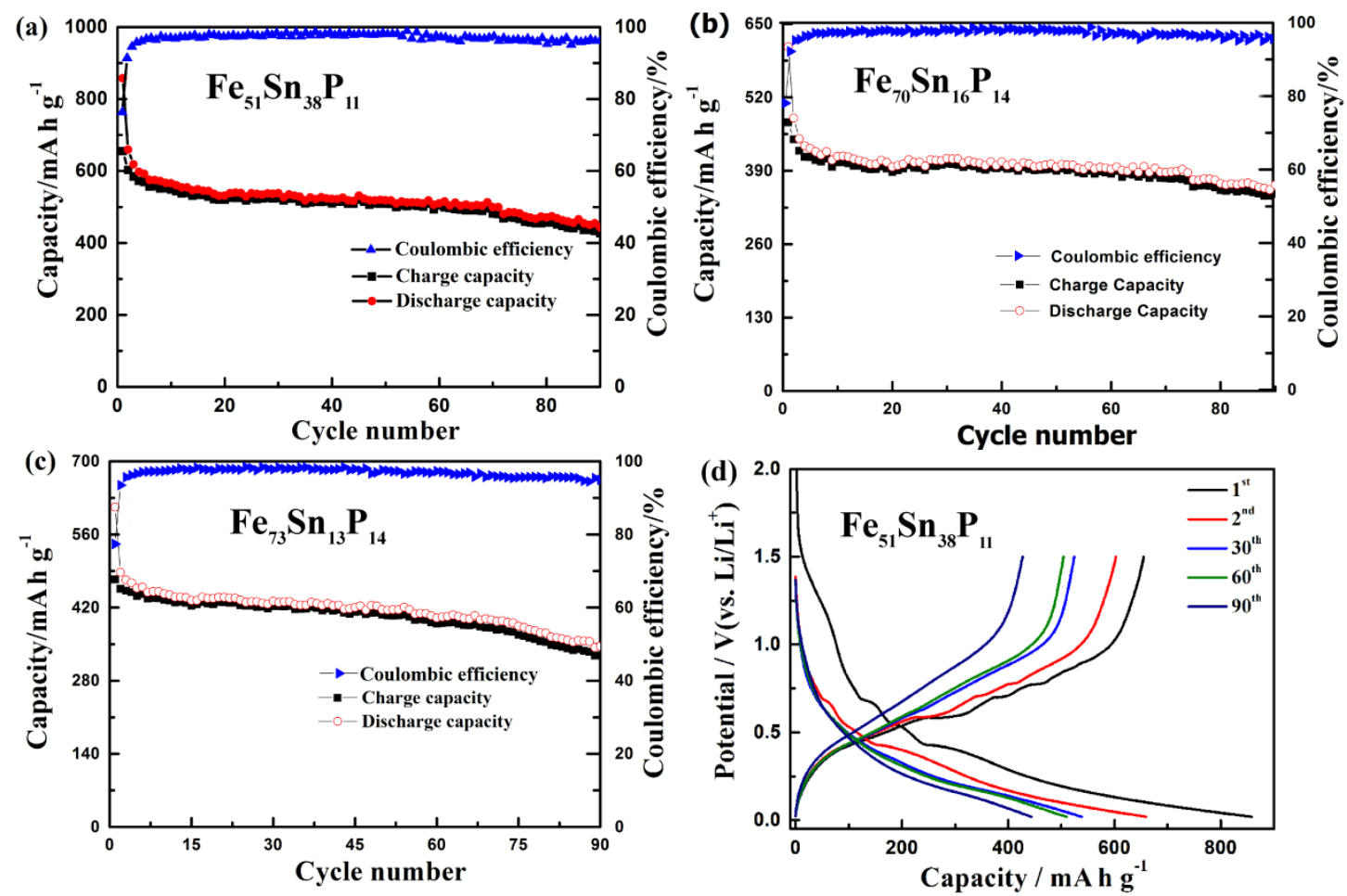

Figure 4 


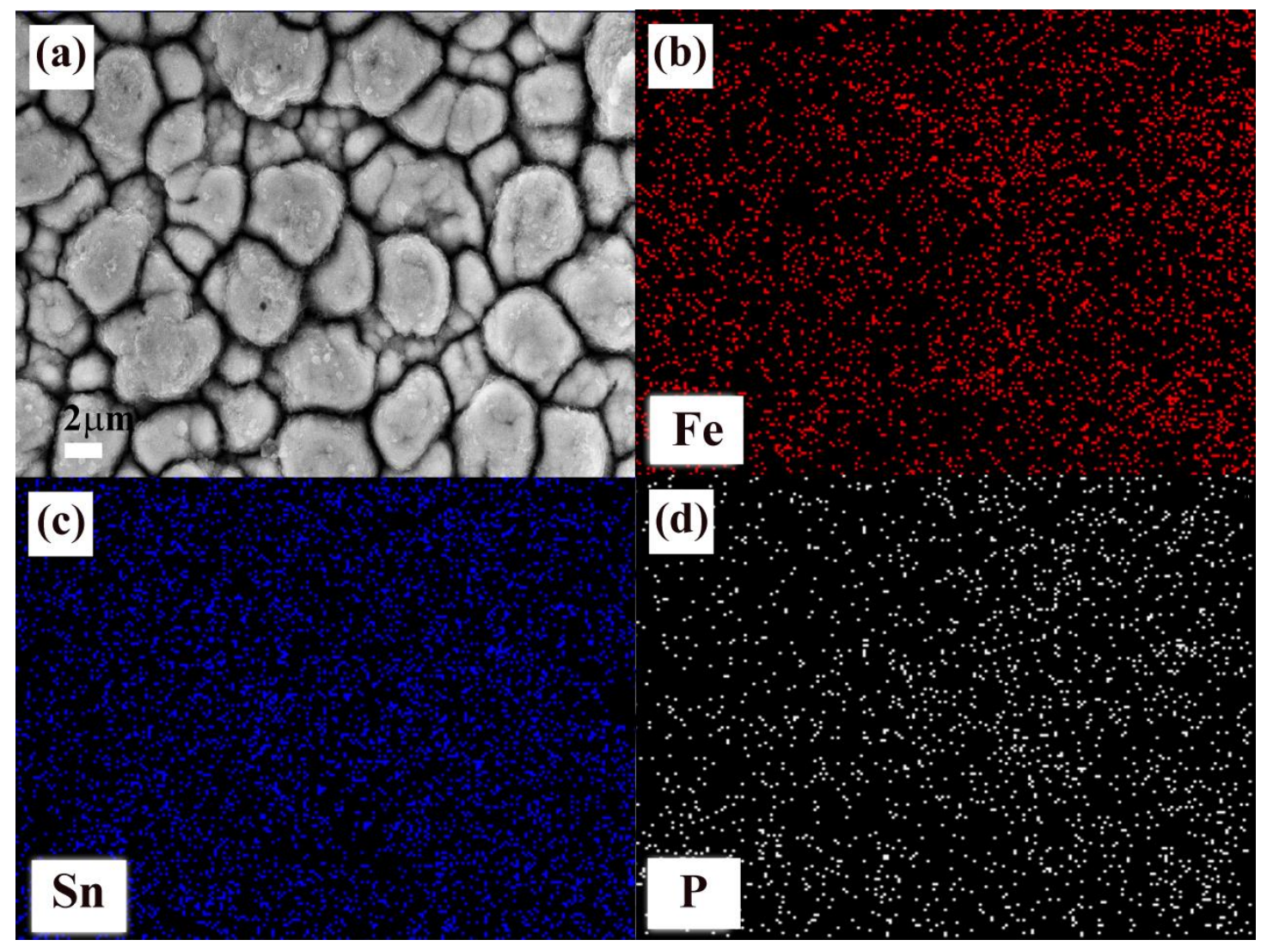

Figure 5 